\title{
Analisis Risiko Rantai Pasok Dinding Beton Pracetak Pada Proyek Pembangunan Apartemen Puncak Dharmahusada Surabaya
}

\author{
Marlinda Dewi Puspita dan Cahyono Bintang Nurcahyo \\ Departemen Teknik Sipil, Fakultas Teknik Sipil dan Perencanaan, Institut Teknologi Sepuluh Nopember (ITS) \\ e-mail: bintang@ce.its.ac.id
}

\begin{abstract}
Abstrak-Arus urbanisasi dan angka kelahiran yang terus meningkat di wilayah perkotaan seperti Surabaya, menyebabkan ketersediaan lahan untuk tempat tinggal semakin terbatas. Sehingga para investor berupaya untuk menciptakan hunian secara vertikal yang diperuntukkan bagi kalangan dengan ekonomi menengah ke atas. Salah satu komponen yang penting dalam pembangunan ini adalah dinding beton pracetak pada dinding luar. Komponen ini sering mengalami ketidakpastian khususnya pada rantai pasok yang dapat menyebabkan keterlambatan jadwal yang telah disepakati sehingga berimbas pada pembengkakan biaya. Oleh karena itu, penelitian ini bertujuan untuk menganalisis risiko dari sisi rantai pasok dan memberikan upaya penanggulangan risiko yang terjadi di sisi rantai pasok pada pembangunan Apartemen Puncak Dharmahusada Surabaya. Penelitian ini dimulai dengan melakukan survei pendahuluan kepada pihak - pihak yang terkait, yaitu kontraktor dan pemasok dinding beton pracetak. Penelitian ini dilakukan dengan mengidentifikasi risiko dalam lima aliran, yaitu aliran material atau fisik, aliran finansial, aliran informasi, aliran relasional, dan aliran inovasi. Survei pendahuluan menghasilkan variabel yang relevan, sehingga dapat digunakan sebagai acuan dalam melakukan survei utama untuk mendapatkan nilai persepsi probabilitas dan dampak dari variabel risiko. Dari hasil survei utama, data ini akan diolah dengan matriks probabilitas risiko serta dampak risiko, sehingga dapat diketahui variabel yang termasuk dalam kategori tinggi. Dari hasil analisis data, maka dapat diketahui bahwa dari persepsi kontraktor terhadap stabilitasrantai pasok dinding beton pracetak terdapat 5 variabel dengan risiko tinggi yang terdapat aliran material/fisik, aliran finansial Untuk persepsi pemasok dinding beton pracetak terdapat 4 variabel dengan risiko tinggi yang terdapat aliran material/fisik, aliran finansial, aliran informasi dan aliran relasional. Dari beberapa variabel yang berisiko tinggi, pihak-pihak yang terkait dalam aktivitas rantai pasok proyek memilih opsi respon risiko secara preventif dan kuratif.
\end{abstract}

Kata Kunci-Analisis Risiko, Apartemen, Dinding Beton Pracetak, Rantai Pasok.

\section{PENDAHULUAN}

\section{A. Latar Belakang}

Seiring dengan peningkatan arus urbanisasi dan bertambahnya angka kelahiran (Data BPS Kota Surabaya tahun 2016), menyebabkan meningkatnya kepadatan penduduk per $\mathrm{km}^{2}$ yang berarti berkurangnya lahan hunian konvensional atau perumahan. Dengan kondisi seperti ini, beberapa investor seperti PT. Puncak Dharmahusada mulai melihat peluang usaha untuk membangun hunian vertikal seperti apartemen yang memiliki harga jual yang cukup tinggi karena diperuntukkan bagi kalangan ekonomi menengah ke atas.

Dalam proses konstruksi apartemen, adanya faktor ketidakpastian dapat menimbulkan berbagai macam risiko salah satunya risiko rantai pasok pada dinding beton pracetak pada dinding luar.

Sistem rantai pasok pada dinding beton pracetak dapat berpotensi mengalami beberapa risiko, sehingga banyak proyek konstruksi yang mengalami keterlambatan dari jadwal yang ditentukan. Kerugian yang ditimbulkan akibat ketidaksesuaian jadwal dapat menyebabkan pembengkakan biaya pada proyek konstruksi. Sehingga perlu adanya analisa risiko khususnya pada rantai pasok untuk dapat mengidentifikasi risiko mana saja yang berpotensi menghambat pekerjaan, dan kemudian dapat diminimalisir.

\section{B. Tujuan Penelitian}

Tujuan dari penelitian ini adalah sebagai berikut:

1. Mengidentifikasi kemungkinan risiko dalam aktivitas rantai pasok dinding beton pracetak yang dapat terjadi.

2. Mengetahui kemungkinan risiko kategori tinggi dalam aktivitas rantai pasok dinding beton pracetak yang terjadi.

3. Mengetahui upaya-upaya apa saja yang dilakukan dalam penanganan kemungkinan risiko dengan kategori tinggi dalam aktivitas rantai pasok dinding beton pracetak yang dapat terjadi.

\section{Batasan Masalah}

Batasan masalah dari penelitian ini adalah sebagai berikut:

1. Risiko yang diteliti adalah risiko dalam aktivitas rantai pasok pada hubungan kerja antara kontraktor dengan pemasok dinding beton pracetak dan pemasok dinding beton pracetak dengan kontraktor.

2. Variabel-variabel risiko dalam aktivitas rantai pasok yang ditinjau pada penelitian ini yaitu variabel aliran material/fisik, aliran finansial, aliran informasi, aliran relasional, dan aliran inovasi.

3. Material dinding beton pracetak diaplikasikan pada bagian dinding luar apartemen

\section{METODOLOGI}

\section{A. Diagram Alir Penelitian}

Berikut ini merupakan diagram alir penelitian yang ditunjukan pada gambar 1 berikut ini. 


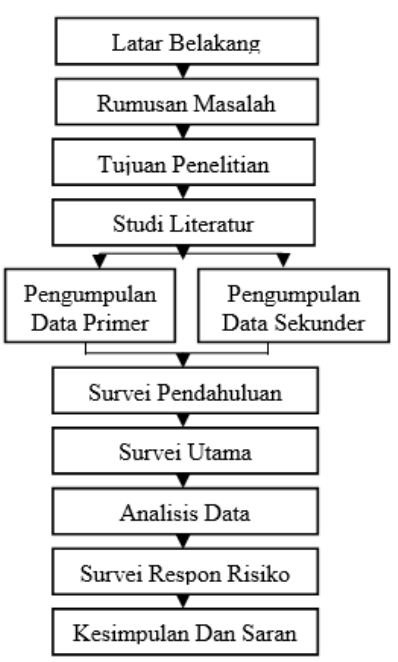

Gambar 1. Diagram Alir Penelitian.

\section{B. Data Penelitian}

Terdapat dua data yang digunakan dalam penelitan ini yang akan dijelaskan pada tabel 1 berikut ini.

Tabel 1.

Data Penelitian

\begin{tabular}{cl}
\hline \hline Data Primer & \multicolumn{1}{c}{ Data Sekunder } \\
\hline Data primer diperoleh dari hasil & \multicolumn{1}{c}{ Data sekunder yang } \\
penyebaran kuesioner terkait risiko & digunakan pada penelitian ini \\
rantai pasok dan wawancara & adalah : Data umum proyek dan \\
secara langsung kepada responden & sistem rantai pasok yang terjadi \\
dari pihak - pihak terkait seperti & pada proyek pembangunan \\
kontraktor (PT. Wijaya Karya & Apartemen \\
Gedung), pemasok dinding beton & Dharmahusada Surabaya yancak \\
pracetak (CV. Amanah Abad & sedang dalam proses \\
& pembangunan.
\end{tabular}

\section{Penerapan Rantai Pasok}

Penerapan rantai pasok pada proyek Apartemen Puncak Dharmahusada Surabaya ialah sebagai berikut:

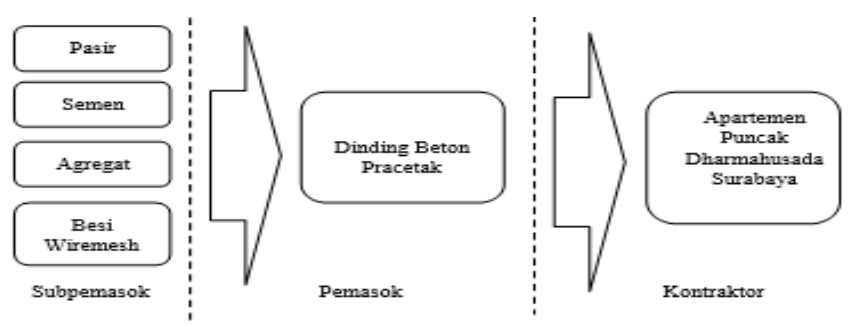

Gambar 2. Penerapan Aktivitas Rantai Pasok Dinding Beton Pracetak Pada Proyek Apartemen Puncak Dharmahusada Surabaya.

\section{Variabel Penelitian}

Penelitian ini bertujuan untuk mengidentifikasi risiko aktivitas rantai pasok yang terjadi pada dinding beton pracetak. Berikut ini adalah variabel risiko persepsi kontraktor terhadap aktivitas dinding beton pracetak yang terdapat pada tabel 2 [1][2].

Tabel 2.

Variabel Risiko Persepsi Kontraktor Terhadap Aktivitas Rantai Pasok Dinding Beton Pracetak

\begin{tabular}{cl}
\hline Kode & \multicolumn{3}{c}{ Variabel Risiko Pada Aliran Material/Fisiko } \\
A1 & $\begin{array}{l}\text { Kelangkaan material yang menyebabkan tidak tepat waktu dalam } \\
\text { pengiriman }\end{array}$ \\
Kegagalan dalam pengiriman material yang diakibatkan oleh kecelakaan \\
\hline
\end{tabular}

\begin{tabular}{|c|c|}
\hline & lalu lintas \\
\hline A3 & Ketidakstabilan suplai material oleh pemasok kepada pihak kontarktor \\
\hline A4 & $\begin{array}{l}\text { Keterlambatan dalam pengiriman material yang diakibatkan oleh cuaca } \\
\text { yang buruk }\end{array}$ \\
\hline A5 & $\begin{array}{l}\text { Ketidaksesuaian antara jumlah material yang dikirim oleh pemasok kepada } \\
\text { pihak kontraktor dengan jumlah permintaan dari pihak kontraktor }\end{array}$ \\
\hline A6 & $\begin{array}{l}\text { Kegagalan pengiriman material yang dikirim oleh pemasok kepada pihak } \\
\text { kontraktor karena lokasi proyek yang kurang jelas atau sulit dilalui }\end{array}$ \\
\hline A7 & $\begin{array}{l}\text { Ketidaksesuaian mutu/kualitas material yang dikirim oleh pemasok kepada } \\
\text { pihak kontraktor terhadap standar mutu sesuai spesifikasi pada kontrak }\end{array}$ \\
\hline A8 & $\begin{array}{l}\text { Risiko akibat persyaratan ketat yang berlaku di sekitar lingkungan proyek } \\
\text { terkait pengadaan material oleh pemasok kepada kontraktor ke lokasi } \\
\text { proyek }\end{array}$ \\
\hline A9 & mbatasan impor material dan peralatan \\
\hline Kode & Variabel risiko Pada Aliran Finansial \\
\hline A10 & $\begin{array}{l}\text { Pembayaran yang terlambat atau bahkan tidak terbayarnya pemasok karena } \\
\text { keuangan kontraktor yang bermasalah }\end{array}$ \\
\hline A11 & $\begin{array}{l}\text { Harga yang diberikan oleh pemasok kepada pihak kontraktor kurang } \\
\text { kompetitif }\end{array}$ \\
\hline $\mathrm{A} 12$ & Kesalahan dalam estimasi biaya \\
\hline A13 & $\begin{array}{l}\text { Frekuensi pembayaran yang dilakukan oleh pihak kontraktor kepada } \\
\text { pemasok }\end{array}$ \\
\hline A14 & $\begin{array}{l}\text { Perubahan harga material yang dipasok akibat eskalasi kenaikan harga } \\
\text { material }\end{array}$ \\
\hline A15 & iko akibat fluktuasi kurs mata uang \\
\hline A16 & Terjadi peningkatan tarif pro \\
\hline A17 & Terjadinya krisis ekonomi \\
\hline A18 & $\begin{array}{l}\text { Tidak sesuainya harga yang dibayarkan oleh kontraktor dengan dengan } \\
\text { harga yang diberikan oleh pemasok }\end{array}$ \\
\hline Kode & Variabel Risiko Pada Aliran Informasi \\
\hline A19 & Ketidakjelasan pemasok dalam memberikan informasi \\
\hline $\mathrm{A} 20$ & $\begin{array}{l}\text { Perubahan spesifikasi dari material yang telah dipesan oleh kontraktor } \\
\text { kepada pihak pemasok }\end{array}$ \\
\hline A21 & Minimnya kepercayaan kontraktor terhadap pemasok \\
\hline A22 & Negosiasi tidak berjalan lancar dengan pihak pemasok \\
\hline A23 & $\begin{array}{l}\text { Minimnya sumber daya alat dan / atau manusia yang dimiliki perusahaan } \\
\text { pada proses pertukaran informasi }\end{array}$ \\
\hline A24 & $\begin{array}{l}\text { Pengajuan klaim dari pihak kontraktor atas ketidakpuasan material yang } \\
\text { telah dikirim oleh pemasok }\end{array}$ \\
\hline A 25 & Manipulasi informasi oleh pemasok \\
\hline A26 & $\begin{array}{l}\text { Tidak adanya petunjuk penggunaan peralatan dan material oleh pemasok } \\
\text { kepada kontraktor }\end{array}$ \\
\hline A27 & Kurang baiknya proses pengawasan dokumen pengadaan \\
\hline A 28 & $\begin{array}{l}\text { Minimnya frekuensi diadakannya rapat koordinasi antara pihak - pihak } \\
\text { yang terlibat dalam proses konstruksi }\end{array}$ \\
\hline Kode & Variabel Risiko Pada Aliran Relasional \\
\hline A29 & $\begin{array}{l}\text { Hubungan psikologis yang terganggu terkait adanya konsekuensi atas } \\
\text { pelanggaran yang dilakukan oleh pemasok }\end{array}$ \\
\hline $\mathrm{A} 30$ & Kesulitan mencari pemasok pengganti \\
\hline A 31 & Kurangnya kesadaran pemasok dalam membina hubungan jangka panjang \\
\hline A32 & mol carin molom \\
\hline A33 & Koordinasi yang lemah deng \\
\hline Kode & Variabel Risiko Pada Aliran Inovasi \\
\hline $\mathrm{A} 34$ & $\begin{array}{l}\text { Pembengkakan biaya konstruksi dengan adanya metode konstruksi yang } \\
\text { baru }\end{array}$ \\
\hline A35 & $\begin{array}{l}\text { Desain engineering detail yang belum lengkap sehingga menyebabkan } \\
\text { perubahan kuantitas item pekerjaan }\end{array}$ \\
\hline A36 & Pengaturan Layout proyek dan relokasi proyek \\
\hline A 37 & $\begin{array}{l}\text { Ketidakpastian kualitas hasil pekerjaan dengan adanya metode konstruksi } \\
\text { yang baru }\end{array}$ \\
\hline A38 & $\begin{array}{l}\text { Spesifikasi dan mutu material yang tidak tercapai dengan persyaratan yang } \\
\text { telah ditetapkan terkait adanya inovasi }\end{array}$ \\
\hline $\mathrm{A} 39$ & Tidak tersedianya material dengan adanya metode konstruksi yang baru \\
\hline
\end{tabular}

Untuk variabel risiko persepsi pemasok terhadap aktivitas rantai pasok dinding beton pracetak juga menggunakan variabel yang sama dengan Tabel 2 tersebut, tetapi dengan perubahan kode A1 hingga A39 menjadi B1 hingga B39. Variabel penelitian ini dibagi mejadi lima aliran, antara lain aliran material/fisik, aliran finansial, aliran informasi, aliran relasional, dan aliran inovasi [3].

\section{E. Responden Penelitian}

Penelitian ini dilakukan dengan melibatkan beberapa responden, antara lain responden dari pihak kontraktor yang terdiri dari :

\section{Site Manager}


2. Manager Konstruksi

3. Staff Pengadaan

4. Pelaksana

5. Pelaksana Struktur

Responden dari pihak pemasok dinding beton pracetak pada dinding luar terdiri dari :
1. Kepala CV
2. Quality Control

\section{F. Instrumen Penelitian}

Kuesioner merupakan instrumen penilaian yang digunakan untuk mengetahui probabilitas dan dampak risiko. Skala peilaian yang digunakan menggunakan skala likert yaitu skala penilaian risiko dengan skala 0 sampai 4 yang menunjukan probabilitas terjadinya risiko yang terjadi di lapangan [4] dengan penjelasan berikut:

1. Angka $0=$ no happen / tidak pernah terjadi

2. Angka $1=$ rarely $/$ jarang terjadi

3. Angka $2=$ sometimes $/$ kadang-kadang terjadi

4. Angka $3=$ often $/$ sering terjadi

5. Angka $4=$ always $/$ sangat sering terjadi

Untuk Dampak terjadinya risiko juga menggunakan skala 0 sampai 4 seperti penjelasan dibawah ini:

1. Angka $0=n o /$ tidak memiliki dampak

2. Angka $1=$ little $/$ memiliki dampak yang kecil

3. Angka $2=$ moderate $/$ memiliki dampak yang sedang

4. Angka $3=$ very $/$ memiliki dampak yang besar

5. Angka $4=$ extremely $/$ memiliki dampak sangat besar

\section{G. Teknik Pengumpulan Data}

Dalam pengumpulan data dilakukan tiga tahapan, seperti yang dijelaskan pada tabel 3 berikut

Tabel 3.

Tahapan Survei dalam Penelitian

\begin{tabular}{|c|c|}
\hline $\begin{array}{c}\text { 1. Survei } \\
\text { Pendahuluan }\end{array}$ & $\begin{array}{l}\text { Survei dilakukan untuk mendapatkan variabel yang relevan } \\
\text { yang sebelumnya didapatkan dari studi literatur. }\end{array}$ \\
\hline 2. Survei Utama & $\begin{array}{l}\text { Pada survei ini responden diminta untuk memberikan } \\
\text { penilaian persepsinya terkait probabilitas dan dampak } \\
\text { risiko pada masing-masing variabel disemua aliran. }\end{array}$ \\
\hline $\begin{array}{l}\text { 3. Survei } \\
\text { Respon Risiko }\end{array}$ & $\begin{array}{l}\text { Survei ini bertujuan untuk mengetahui cara penanganan } \\
\text { terhadap variabel yang memiliki risiko tinggi dalam } \\
\text { aktivitas rantai pasok dinding beton pracetak pada } \\
\text { pembangunan Apartemen Puncak Dharmahusada } \\
\text { Surabaya. }\end{array}$ \\
\hline
\end{tabular}

\section{ANALISIS DATA DAN PEMBAHASAN}

\section{A. Hail Survei Pendahuluan}

Hasil dari survei pendahuluan menyatakan bahwa semua variabel risiko yang didapatkan oleh penulis dari literatur seluruhnya relevan dengan yang ada di lapangan.

\section{B. Hasil Survei Utama}

Setelah dilakukan survei pendahuluan, maka dilakukan survei utama untuk mengerti penilaian persepsi probabilitas dan dampak pada masing-masing pihak. Tabel 4 berikut ini merupakan contoh hasil pengolahan data dari hasil survei utama yang diambil dari variabel dari kode A17 pada Tabel 2.

Tabel 4.

Persepsi Nilai Probabilitas dan Dampak Terhaap Variabel Risiko Terjadinya Krisis Ekonomi

\begin{tabular}{|c|c|c|c|c|c|c|c|c|c|c|c|}
\hline \multirow[t]{2}{*}{ kode } & \multirow[t]{2}{*}{$\begin{array}{l}\text { Variabel } \\
\text { Risiko }\end{array}$} & \multicolumn{5}{|c|}{ Probabilitas Risiko } & & & Per & & \\
\hline & & 0 & 1 & 2 & 3 & 4 & 0 & 1 & 2 & 3 & 4 \\
\hline A17 & $\begin{array}{l}\text { Terjadinya } \\
\text { krisis } \\
\text { ekonomi }\end{array}$ & 0 & 4 & 1 & 0 & 0 & 0 & 0 & 3 & 1 & 1 \\
\hline
\end{tabular}

Dari penilaian persepsi mengenai probabilitas risiko pada lima responden, 4 responden menyatakan bahwa risiko tersebut jarang terjadi (skala 1) dan 1 responden menyatakan bahwa risiko tersebut kadang-kadang terjadi (skala 2). Dari penilaian persepsi mengenai dampak risiko pada lima responden dari lima responden, 3 responden menyatakan bahwa risiko tersebut menimbulkan dampak yang sedang (skala 2), 1 responden menyatakan bahwa risiko tersebut menimbulkan dampak yang besar (skala 3), dan 1 responden menyatakan bahwa risiko tersebut menimbulkan dampak yang sangat besar (skala 4).

Kemudian dilakukan perhitungan Probability Index dan Impact Index, berdasarkan rumus Frequency Index dan Severity Index [4] :

Menghitung nilai Probability Index

$$
\begin{aligned}
\mathrm{PI}= & \frac{\sum_{i=0}^{4} a_{i}^{x_{1}}}{4 \sum_{i=0}^{4} x_{i}} x 100 \% \\
& \frac{(0 \times 0)+(4 x 1)+(1 \times 2)+(0 \times 3)+(0 \times 4)}{4(0+4+1+0+0)} \times 100 \%=30 \%
\end{aligned}
$$

Menghitung nilai Impact Index

$$
\begin{aligned}
\mathrm{II}= & \frac{\sum_{\mathrm{i}=0}^{4} a_{i}^{x_{1}}}{4 \sum_{i=0}^{4} x_{i}^{x_{1}}} x 100 \% \\
& \frac{(0 x 0)+(0 x 1)+(3 \times 2)+(1 \times 3)+(1 \times 4)}{4(0+0+3+1+1)} \times 100 \%=65 \%
\end{aligned}
$$

Nilai PI dan II tersebut kemudian dikelompokan sesuai dengan klasifikasi [5] pada tabel 5

Tabel 5.

Klasifikasi Nilai PI dan II

\begin{tabular}{cc}
\hline \hline Klasifikasi & Keterangan \\
\hline $0 \%<$ PI $\leq 20 \%$ & Sangat Rendah / Very Low \\
$21 \%<$ PI $\leq 40 \%$ & Rendah / Low \\
$41 \%<$ PI $\leq 60 \%$ & Cukup / Moderate \\
$61 \%<$ PI $\leq 80 \%$ & Tinggi / High \\
$81 \%<$ PI $\leq 100 \%$ & Sangat Tinggi / Very High \\
\hline \hline
\end{tabular}

Setelah mendapatkan nilai PI dan II dari masing-masing variabel, setelah itu dilakukan pemetaan nilai tersebut pada Matriks Probabilitas dan Dampak berdasarkan PMBOK tahun 2013 [6]. Pemetaan tersebut dilakukan untuk mengetahui setiap variabel risiko tersebut termasuk dalam kategori rendah (hijau), sedang (kuning), tinggi (merah) seperti yang ditunjukan pada gambar3 berikut.

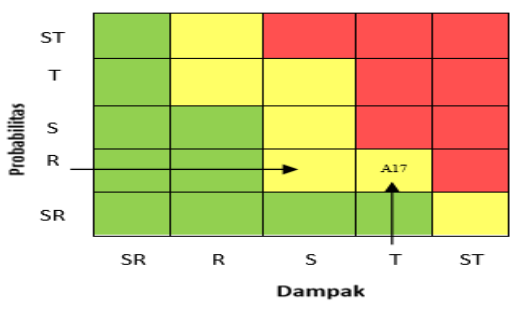

Gambar 3. Matriks Probabilitas dan Dampak variabel A17 
Berikut merupakan hasil survei utama hubungan kerja pada masing-masing pihak beserta hasil nilai risiko yang didapat dari pemetaan Matriks Probabilitas dan Dampak Risiko yang telah dijabarkan pada tabel 6 dan tabel 7 sebagai berikut.

Tabel 6.

Hasil Penilian Persepsi Kontraktor Terhadap Aktivitas Rantai Pasok Dinding

\begin{tabular}{|c|c|c|c|c|c|}
\hline \multicolumn{6}{|c|}{ Beton Pracetak } \\
\hline \multirow[b]{2}{*}{ Kode } & \multicolumn{2}{|c|}{ Probability Index } & \multicolumn{2}{|c|}{ Impact Index } & \multirow[b]{2}{*}{$\begin{array}{l}\text { Nilai } \\
\text { Risiko }\end{array}$} \\
\hline & $\begin{array}{l}\text { Prosen } \\
\text { tase }\end{array}$ & $\begin{array}{l}\text { Klasifi } \\
\text { kasi }\end{array}$ & $\begin{array}{l}\text { Prosen } \\
\text { tase }\end{array}$ & $\begin{array}{l}\text { Klasifi } \\
\text { kasi }\end{array}$ & \\
\hline A1 & 40 & $\mathrm{R}$ & 75 & $\mathrm{~T}$ & $\mathrm{~S}$ \\
\hline A2 & 35 & $\mathrm{R}$ & 70 & $\mathrm{~T}$ & $\mathrm{~S}$ \\
\hline $\mathbf{A 3}$ & 35 & $\mathbf{R}$ & 85 & ST & $\mathbf{T}$ \\
\hline $\mathrm{A} 4$ & 25 & $\mathrm{R}$ & 70 & $\mathrm{~T}$ & $\mathrm{~s}$ \\
\hline A5 & 40 & $\mathbf{R}$ & 85 & ST & $\mathbf{T}$ \\
\hline A6 & 25 & $\mathrm{R}$ & 50 & $\mathrm{~S}$ & $\mathrm{~S}$ \\
\hline A7 & 55 & $\mathrm{~S}$ & 55 & $\mathrm{~S}$ & $\mathrm{~S}$ \\
\hline A8 & 30 & $\mathrm{R}$ & 65 & $\mathrm{~T}$ & $\mathrm{~S}$ \\
\hline A9 & 25 & $\mathrm{R}$ & 60 & $\mathrm{~s}$ & $\mathrm{~s}$ \\
\hline A10 & 45 & $\mathrm{~S}$ & 60 & $\mathrm{~S}$ & $\mathrm{~S}$ \\
\hline A11 & 35 & $\mathbf{R}$ & 85 & ST & $\mathbf{T}$ \\
\hline $\mathrm{A} 12$ & 30 & $\mathrm{R}$ & 65 & $\mathrm{~T}$ & $\mathrm{~s}$ \\
\hline A13 & 35 & $\mathrm{R}$ & 60 & $\mathrm{~S}$ & $\mathrm{~S}$ \\
\hline A14 & 45 & $\mathbf{S}$ & 65 & $\mathbf{T}$ & $\mathbf{T}$ \\
\hline A15 & 30 & $\mathrm{R}$ & 65 & $\mathrm{~T}$ & $\mathrm{~S}$ \\
\hline A16 & 40 & $\mathrm{R}$ & 55 & $\mathrm{~S}$ & $\mathrm{~S}$ \\
\hline A17 & 30 & $\mathrm{R}$ & 65 & $\mathrm{~T}$ & $\mathrm{~S}$ \\
\hline A18 & 25 & $\mathrm{R}$ & 70 & $\mathrm{~T}$ & $\mathrm{~S}$ \\
\hline A19 & 35 & $\mathrm{R}$ & 55 & $\mathrm{~s}$ & $\mathrm{~s}$ \\
\hline $\mathrm{A} 20$ & 30 & $\mathrm{R}$ & 40 & $\mathrm{R}$ & $\mathrm{R}$ \\
\hline A21 & 50 & $\mathrm{~S}$ & 60 & $\mathrm{~S}$ & $\mathrm{~S}$ \\
\hline A22 & 35 & $\mathrm{R}$ & 55 & $\mathrm{~S}$ & $\mathrm{~S}$ \\
\hline A23 & 25 & $\mathrm{R}$ & 50 & $\mathrm{~S}$ & $\mathrm{~S}$ \\
\hline A24 & 45 & $\mathrm{~s}$ & 45 & $\mathrm{~s}$ & $\mathrm{~S}$ \\
\hline A25 & 25 & $\mathrm{R}$ & 60 & $\mathrm{~S}$ & $\mathrm{~S}$ \\
\hline A26 & 25 & $\mathrm{R}$ & 70 & $\mathrm{~T}$ & $\mathrm{~S}$ \\
\hline A27 & 30 & $\mathrm{R}$ & 45 & $\mathrm{~S}$ & $S$ \\
\hline A28 & 25 & $\mathrm{R}$ & 65 & $\mathrm{~T}$ & $S$ \\
\hline A29 & 20 & SR & 50 & S & $\mathrm{R}$ \\
\hline $\mathrm{A} 30$ & 30 & $\mathrm{R}$ & 55 & S & $S$ \\
\hline A31 & 45 & $\mathrm{~S}$ & 50 & S & $S$ \\
\hline A32 & 20 & SR & 65 & $\mathrm{~T}$ & $\mathrm{R}$ \\
\hline A33 & 30 & $\mathrm{R}$ & 70 & $\mathrm{~T}$ & $S$ \\
\hline A34 & 45 & $\mathbf{S}$ & 65 & $\mathbf{T}$ & $\mathbf{T}$ \\
\hline A35 & 35 & $\mathrm{R}$ & 70 & $\mathrm{~T}$ & $\mathrm{~S}$ \\
\hline A36 & 35 & $\mathrm{R}$ & 45 & S & $S$ \\
\hline A37 & 25 & $\mathrm{R}$ & 65 & $\mathrm{~T}$ & S \\
\hline A38 & 45 & $\mathrm{~S}$ & 55 & S & $\mathrm{S}$ \\
\hline A39 & 30 & $\mathrm{R}$ & 65 & $\mathrm{~T}$ & $S$ \\
\hline
\end{tabular}

Tabel 7.

Hasil Penilaian Persepsi Pemasok Terhadap Aktivitas Rantai Pasok Dinding Beton Pracetak

\begin{tabular}{cccccc}
\hline \hline Kode & $\begin{array}{c}\text { Probability Index } \\
\text { Prosen } \\
\text { tase }\end{array}$ & $\begin{array}{c}\text { Klasifi } \\
\text { kasi }\end{array}$ & $\begin{array}{c}\text { Impact } \\
\text { Prosen } \\
\text { tase }\end{array}$ & $\begin{array}{l}\text { Index } \\
\text { Klasifi } \\
\text { kasi }\end{array}$ & $\begin{array}{c}\text { Nilai } \\
\text { Risiko }\end{array}$ \\
\hline B1 & $\mathbf{5 0}$ & S & $\mathbf{8 7 , 5}$ & ST & T \\
B2 & 25 & $\mathrm{R}$ & 50 & $\mathrm{~S}$ & $\mathrm{~S}$ \\
B3 & 37,5 & $\mathrm{R}$ & 75 & $\mathrm{~T}$ & S \\
B4 & 12,5 & $\mathrm{SR}$ & 75 & $\mathrm{~T}$ & $\mathrm{R}$ \\
B5 & 25 & $\mathrm{R}$ & 75 & $\mathrm{~T}$ & $\mathrm{~S}$ \\
B6 & 12,5 & $\mathrm{SR}$ & 50 & $\mathrm{~S}$ & $\mathrm{R}$ \\
B7 & 37,5 & $\mathrm{R}$ & 75 & $\mathrm{~T}$ & $\mathrm{~S}$ \\
B8 & 12,5 & $\mathrm{SR}$ & 75 & $\mathrm{~T}$ & $\mathrm{R}$ \\
B9 & 25 & $\mathrm{R}$ & 62,5 & $\mathrm{~T}$ & $\mathrm{~S}$ \\
B10 & 12,5 & $\mathrm{SR}$ & 87,5 & $\mathrm{ST}$ & $\mathrm{S}$ \\
B11 & 25 & $\mathrm{R}$ & 75 & $\mathrm{~T}$ & $\mathrm{~S}$ \\
B12 & 25 & $\mathrm{R}$ & 75 & $\mathrm{~T}$ & $\mathrm{~S}$ \\
B13 & $\mathbf{5 0}$ & $\mathrm{S}$ & $\mathbf{8 7 , 5}$ & ST & T \\
B14 & 25 & $\mathrm{R}$ & 75 & $\mathrm{~T}$ & $\mathrm{~S}$ \\
B15 & 12,5 & $\mathrm{SR}$ & 62,5 & $\mathrm{~T}$ & $\mathrm{R}$ \\
B16 & 37,5 & $\mathrm{R}$ & 50 & $\mathrm{~S}$ & $\mathrm{~S}$ \\
B17 & 25 & $\mathrm{R}$ & 75 & $\mathrm{~T}$ & $\mathrm{~S}$ \\
B18 & 50 & $\mathrm{~S}$ & 50 & $\mathrm{~S}$ & $\mathrm{~S}$ \\
B19 & $\mathbf{5 0}$ & S & $\mathbf{7 5}$ & T & T \\
B20 & 50 & $\mathrm{~S}$ & 50 & $\mathrm{~S}$ & $\mathrm{~S}$ \\
B21 & 25 & $\mathrm{R}$ & 62,5 & $\mathrm{~T}$ & $\mathrm{~S}$ \\
B22 & 37,5 & $\mathrm{~S}$ & 50 & $\mathrm{~S}$ & $\mathrm{~S}$ \\
\hline \hline
\end{tabular}

\begin{tabular}{cccccc}
\hline \hline B23 & 25 & $\mathrm{R}$ & 62,5 & $\mathrm{~T}$ & $\mathrm{~S}$ \\
$\mathrm{~B} 24$ & 25 & $\mathrm{R}$ & 75 & $\mathrm{~T}$ & $\mathrm{~S}$ \\
$\mathrm{~B} 25$ & 50 & $\mathrm{~S}$ & 50 & $\mathrm{~S}$ & $\mathrm{~S}$ \\
$\mathrm{~B} 26$ & 25 & $\mathrm{R}$ & 62,5 & $\mathrm{~T}$ & $\mathrm{~S}$ \\
$\mathrm{~B} 27$ & 12,5 & $\mathrm{SR}$ & 87,5 & $\mathrm{ST}$ & $\mathrm{S}$ \\
$\mathrm{B} 28$ & 25 & $\mathrm{R}$ & 75 & $\mathrm{~T}$ & $\mathrm{~S}$ \\
$\mathrm{~B} 29$ & 25 & $\mathrm{R}$ & 75 & $\mathrm{~T}$ & $\mathrm{~S}$ \\
$\mathrm{~B} 30$ & 37,5 & $\mathrm{R}$ & 62,5 & $\mathrm{~T}$ & $\mathrm{~S}$ \\
B31 & 50 & $\mathrm{~S}$ & 50 & $\mathrm{~T}$ & $\mathrm{~S}$ \\
B32 & 37,5 & $\mathrm{R}$ & 75 & $\mathrm{~T}$ & $\mathrm{~S}$ \\
B33 & $\mathbf{5 0}$ & $\mathrm{S}$ & $\mathbf{6 2 , 5}$ & $\mathrm{T}$ & $\mathrm{T}$ \\
$\mathrm{B} 34$ & 25 & $\mathrm{R}$ & 62,5 & $\mathrm{~T}$ & $\mathrm{~S}$ \\
$\mathrm{~B} 35$ & 25 & $\mathrm{R}$ & 75 & $\mathrm{~T}$ & $\mathrm{~S}$ \\
$\mathrm{~B} 36$ & 12,5 & $\mathrm{SR}$ & 87,5 & $\mathrm{ST}$ & $\mathrm{S}$ \\
$\mathrm{B} 37$ & 37,5 & $\mathrm{R}$ & 75 & $\mathrm{~T}$ & $\mathrm{~S}$ \\
B38 & 50 & $\mathrm{~S}$ & 50 & $\mathrm{~S}$ & $\mathrm{~S}$ \\
$\mathrm{~B} 39$ & 37,5 & $\mathrm{R}$ & 75 & $\mathrm{~T}$ & $\mathrm{~S}$ \\
\hline \hline
\end{tabular}

Untuk lebih jelasnya, pada gambar 4 berikut merupakan variabel-variabel yang memiliki risiko dengan kategori tinggi (warna merah) yang diperoleh dari hasil survei utama dan pemetaan pada Matriks Probabilitas dan Dampak pada pihakpihak terkait.



Gambar 4. Matriks Probabilitas dan Dampak Risiko Penilaian Kontraktor Dan Pemasok

\section{Hasil Survei Respon Risiko}

Survei respon risiko ini dilakukan pada variabel risiko yang berkategori tinggi saja seperti pada tabel 8 dan tabel 9 berikut ini.

Tabel 8.

Hasil Survei Respon Risiko Kontraktor Terhadap Aktivitas Rantai Pasok Dinding Beton Pracetak

\begin{tabular}{|c|c|}
\hline $\begin{array}{l}\text { Variabel } \\
\text { Risiko }\end{array}$ & $\begin{array}{l}\begin{array}{l}\text { Ketidakstabilan suplai material oleh pemasok kepada pihak } \\
\text { kontraktor (A3) }\end{array} \\
\text { k }\end{array}$ \\
\hline $\begin{array}{c}\text { Faktor } \\
\text { Penyebab }\end{array}$ & $\begin{array}{l}\text { 1. Kelangkaan salah satu bahan baku dalam pembuatan dinding } \\
\text { beton pracetak mengingat semua semua lokasi bahan baku saling } \\
\text { berjauhan } \\
2 \text {. Perijinan dari daerah setempat yang membatasi cakupan wilayah } \\
\text { pengambilan bahan baku tertentu }\end{array}$ \\
\hline Dampak & $\begin{array}{l}\text { 1.Kemajuan pekerjaan konstruksi menjadi terhambat dan } \\
\text { menyebabkan keterlambatan pada setiap progresnya } \\
\text { 2. Penambahan biaya upah para pekerja akibat penambahan jam } \\
\text { kerja }\end{array}$ \\
\hline $\begin{array}{l}\text { Strategi } \\
\text { Preventif }\end{array}$ & $\begin{array}{l}\text { 1. Selalu menjalin komunikasi yang baik terhadap pemasok agar } \\
\text { dapat memantau material yang akan dikirim } \\
\text { 2. Menyepakati adanya penalty pelanggaran perjanjian dalam } \\
\text { pembuatan RFQ (Request for Quotation), yang sudah tertera } \\
\text { bentuk perjanjian yang wajib dipenuhi oleh pemasok. } \\
\text { 3.Menyiapkan daftar pemasok cadangan untuk mengantisipasi } \\
\text { pemasok tidak dapat mengirim material }\end{array}$ \\
\hline Strategi Kuratif & $\begin{array}{l}\text { Memberikan penalty pelanggaran kepada pihak pemasok } \\
\text { Mencari pemasok dinding beton pracetak yang lain yang dapat }\end{array}$ \\
\hline & memenuhi permintaan kontraktor pada proyek tersebut \\
\hline $\begin{array}{l}\text { Variabel } \\
\text { Risiko }\end{array}$ & $\begin{array}{l}\text { Ketidaksesuaian antara jumlah material yang dikirim oleh pemasok } \\
\text { kepada pihak kontraktor dengan jumlah permintaan dari pihak } \\
\text { kontraktor (A5) }\end{array}$ \\
\hline $\begin{array}{l}\text { Faktor } \\
\text { Penyebab }\end{array}$ & $\begin{array}{l}\text { 1.Salah dalam perhitungan yang dilakukan oleh pihak pemasok } \\
\text { 2.Kurangnya pengontrolan dari pihak kontraktor untuk mengecek } \\
\text { jumlah material yang telah dikirim }\end{array}$ \\
\hline Dampe & $\begin{array}{l}\text { 1. Kemajuan pekerjaan konstruksi menjadi terlambat karena pada } \\
\text { saat pelaksanaan jumlah material tidak sesuai dengan yang }\end{array}$ \\
\hline
\end{tabular}




\begin{tabular}{|c|c|}
\hline \multirow{4}{*}{$\begin{array}{l}\text { Strategi } \\
\text { Preventif }\end{array}$} & "dibutuhkan sehingga harus menunggu \\
\hline & $\begin{array}{l}\text { 2. Penambahan jam kerja secara otomatis juga berdampak pada } \\
\text { penambahan biaya upah pekerja }\end{array}$ \\
\hline & $\begin{array}{l}\text { 1. Selalu menjalin komunikasi kepada pihak pemasok untuk } \\
\text { memastikan jumlah material yang akan dikirim sesuai Purchase } \\
\text { Order agar tidak terjadi kesalapahaman }\end{array}$ \\
\hline & $\begin{array}{l}\text { 2. Quality Control dari kedua pihak juga harus selalu teliti dalam } \\
\text { pengecekan material yang akan dikirim dan yang telah dikirim }\end{array}$ \\
\hline Strategi & $\begin{array}{l}\text { 1. Meminta pertanggungjawaban dari pihak pemasok untuk segera } \\
\text { mengirim material yang kurang }\end{array}$ \\
\hline Kuratif & $\begin{array}{l}\text { 2. Mencari pemasok dinding beton pracetak yang lain yang dapat } \\
\text { memenuhi permintaan kontraktor pada proyek tersebut }\end{array}$ \\
\hline \multirow[t]{2}{*}{$\begin{array}{l}\text { Variabel } \\
\text { Risiko }\end{array}$} & $\begin{array}{l}\text { Harga yang diberikan oleh pemasok kepada pihak kontraktor } \\
\text { kurang kompetitif (A11) }\end{array}$ \\
\hline & $\begin{array}{l}\text { 1.Pihak CV Amanah Abadi lebih mengutamakan kualitas mutu } \\
\text { yang terjamin agar awet dan kuat pada saat dilakukan pemasangan }\end{array}$ \\
\hline $\begin{array}{c}\text { Faktor } \\
\text { Penyebab }\end{array}$ & $\begin{array}{l}\text { 2. Pemilihan bahan baku yang bagus membuat harga yang } \\
\text { ditawarkan oleh CV Amanah Abadi jauh lebih tinggi dari pemasok } \\
\text { dinding beton pracetak lainnya yang menggunakan bahan baku } \\
\text { yang biasa }\end{array}$ \\
\hline Dampak & $\begin{array}{l}\text { 1. Biaya anggaran proyek tidak dapat ditekan atau diminimalisir } \\
\text { pada pekerjaan pemasangan dinding dinding beton pracetak } \\
\text { 1. Mencari pemasok yang menawarkan harga sesuai dengan }\end{array}$ \\
\hline Strategi & kualitas bagus pada saat proses TBE (Technical Bid Evaluation) \\
\hline Preventif & $\begin{array}{l}\text { 2. Menyiapkan daftar pemasok cadangan yang memiliki harga yang } \\
\text { sesuai dengan keinginan kontraktor }\end{array}$ \\
\hline $\begin{array}{l}\text { Strategi } \\
\text { Kuratif }\end{array}$ & $\begin{array}{l}\text { 1.Menerima harga yang telah ditawarkan oleh pemasok dengan } \\
\text { catatan pihak pemasok dapat memberikan material dengan mutu } \\
\text { yang terjamin } \\
\text { 2. Mencari pemasok dinding beton pracetak yang lain yang } \\
\text { memiliki harga yang sesuai dengan keinginan pihak kontraktor }\end{array}$ \\
\hline $\begin{array}{l}\text { Variabel } \\
\text { Risiko }\end{array}$ & $\begin{array}{l}\text { Perubahan harga material yang dipasok akibat eskalasi kenaikan } \\
\text { harga material (A14) }\end{array}$ \\
\hline $\begin{array}{l}\text { Faktor } \\
\text { Penyebab }\end{array}$ & $\begin{array}{l}\text { 1. Adanya kenaikan tarif } \mathrm{BBM}, \mathrm{UMR} \text {, dalam pengiriman bahan } \\
\text { baku penyedia dinding beton pracetak }\end{array}$ \\
\hline Dampak & $\begin{array}{l}\text { 1. Pembengkakan anggaran proyek, dan bila tidak dapat terkendali } \\
\text { maka akan melebihi dari yang anggaran yang disediakan }\end{array}$ \\
\hline $\begin{array}{l}\text { Strategi } \\
\text { Preventif }\end{array}$ & $\begin{array}{l}\text { 1. Mempersiapkan anggraran yang berlebih sesuai dengan } \\
\text { perkirakan kenaikan atau eskalasi harga material dalam } 3 \text { tahun } \\
\text { terakhir }\end{array}$ \\
\hline $\begin{array}{l}\text { Strategi } \\
\text { Kuratif }\end{array}$ & $\begin{array}{l}\text { 1. Negoisasi kepada pihak pemasok agar perubahan harga yang } \\
\text { diberikan tidak terlalu signifikan }\end{array}$ \\
\hline \multicolumn{2}{|c|}{$\begin{array}{c}\text { Tabel 8. } \\
\begin{array}{c}\text { Hasil Survei Respon Risiko Kontraktor Terhadap Aktivitas Rantai Pasok } \\
\text { Dinding Beton Pracetak (Lanjutan) }\end{array}\end{array}$} \\
\hline $\begin{array}{l}\text { Variabel } \\
\text { Risiko }\end{array}$ & $\begin{array}{l}\text { Pembengkakan biaya konstruksi dengan adanya konstruksi dengan } \\
\text { adanya metode konstruksi yang baru (A34) }\end{array}$ \\
\hline $\begin{array}{l}\text { Faktor } \\
\text { Penyebab }\end{array}$ & $\begin{array}{l}\text { 1.Tidak tertulisnya tambahan metode konstruksi yang baru dalam } \\
\text { kontrak menyebabkan anggaran proyek tidak akurat dan mengalami } \\
\text { pembengkakan pada biaya proyek }\end{array}$ \\
\hline Dampak & $\begin{array}{l}\text { 1.Biaya dari proyek membengkak akibat metode konstruksi yang } \\
\text { baru } \\
\text { 2. Anggaran proyek menjadi tergerus akibat penambahan metode } \\
\text { konstruksi yang baru }\end{array}$ \\
\hline $\begin{array}{l}\text { Strategi } \\
\text { Preventif } \\
\text { Strategi } \\
\text { Kuratif } \\
\end{array}$ & $\begin{array}{l}\text { 1.Memastikan setiap metode konstruksi yang akan dipakai agar } \\
\text { anggaran proyek lebih akurat dan tidak mengalami pembengkakan } \\
\text { 1.Mencari inisiatif untuk menggunakan metode konstruksi baru } \\
\text { yang lebih murah dan efisien. }\end{array}$ \\
\hline \multicolumn{2}{|c|}{$\begin{array}{c}\text { Tabel 9. } \\
\begin{array}{c}\text { Hasil Survei Respon Risiko Pemasok Terhadap Aktivitas Rantai Pasok } \\
\text { Dinding Beton Pracetak }\end{array} \\
\end{array}$} \\
\hline $\begin{array}{l}\text { Variabel } \\
\text { Risiko }\end{array}$ & $\begin{array}{l}\text { Kelangkaan material yang menyebabkan tidak tepat waktu dalam } \\
\text { pengiriman (B1) }\end{array}$ \\
\hline $\begin{array}{c}\text { Faktor } \\
\text { Penyebab }\end{array}$ & $\begin{array}{l}\text { 1. Beberapa subpemasok mengalami kelangkaan bahan baku yang } \\
\text { disebabkan peraturan daerah terkait pembatasan ijin }\end{array}$ \\
\hline Dampak & $\begin{array}{l}\text { 1. Pengiriman dinding beton pracetak kepada pihak kontraktor jadi } \\
\text { terhambat }\end{array}$ \\
\hline $\begin{array}{l}\text { Strategi } \\
\text { Preventif }\end{array}$ & $\begin{array}{l}\text { 1. Pihak pemasok menyiapkan stok dinding beton pracetak yang } \\
\text { berlebih untuk mengantisipasi jika salah satu subpemasok tidak } \\
\text { dapat mengirim tepat waktu }\end{array}$ \\
\hline Strategi & 1. Pihak pemasok mencari material pengganti untuk dikirim kepada \\
\hline Variabel & Frekuensi pembayaran yang dilakukan oleh pihak kontraktor \\
\hline Risiko & \\
\hline & 1. Keadaan finansial dari pihak kontraktor sedang tidak stabil \\
\hline $\begin{array}{l}\text { Faktor } \\
\text { Penyebab }\end{array}$ & $\begin{array}{l}\text { 2. Kurang mutakhirnya informasi dari bgaian keuangan sehingga } \\
\text { apabila terjadi kesalahan invoice perlu waktu cukup yang lama } \\
\text { untuk pengecekan }\end{array}$ \\
\hline Dampak & $\begin{array}{l}\text { 1. Cash flow pemasok terganggu dan biaya operasional terhambat } \\
\text { 2.Proses pengiriman menjadi terhambat }\end{array}$ \\
\hline
\end{tabular}

\begin{tabular}{|c|c|}
\hline $\begin{array}{l}\text { Strategi } \\
\text { Preventif }\end{array}$ & $\begin{array}{l}\text { 1.Selalu aktif dalam berkomunikasi dengan bagian keuangan dan } \\
\text { logistik pada pihak kontraktor sebelum pengiriman material dan } \\
\text { penagihan invoice }\end{array}$ \\
\hline $\begin{array}{l}\text { Strategi } \\
\text { Kuratif }\end{array}$ & $\begin{array}{l}\text { 1.Bernegosiasi kepada pihak kontraktor untuk menyelesaikan } \\
\text { pembayaran }\end{array}$ \\
\hline $\begin{array}{l}\text { Variabel } \\
\text { Risiko }\end{array}$ & Ketidakjelasan kontraktor dalam memberikan informasi (B19) \\
\hline Faktor & $\begin{array}{l}\text { 1.Kontraktor belum memastikan dalam memberikan keterangan } \\
\text { terkait jumlah dinding beton pracetak yang telah dipesan }\end{array}$ \\
\hline Penyebab & $\begin{array}{l}\text { 2.Kontraktor belum memastikan dalam memberikan keterangan } \\
\text { kapan material dikirim ke lokasi proyek }\end{array}$ \\
\hline Dampak & $\begin{array}{l}\text { 1.Pengiriman material yang akan dikirim tidak sesuai jumlahnya } \\
\text { 2. Terjadi kesalapahaman antara pihak pemasok dengan pihak } \\
\text { kontraktor }\end{array}$ \\
\hline $\begin{array}{l}\text { Strategi } \\
\text { Preventif }\end{array}$ & $\begin{array}{l}\text { 1.Pemasok sering melakukan komunikasi kepada pihak kontraktor } \\
\text { untuk memastikan jadwal pengiriman dan jumlah material yang } \\
\text { dikirim }\end{array}$ \\
\hline $\begin{array}{l}\text { Strategi Risiko } \\
\quad \text { Kuratif }\end{array}$ & $\begin{array}{l}\text { 1. Mengecek kembali jumlah material yang dikirim pada PO dan } \\
\text { Material Document yang di input }\end{array}$ \\
\hline $\begin{array}{l}\text { Variabel } \\
\text { Risiko }\end{array}$ & Koordinasi yang lemah dengan kontraktor (B33) \\
\hline Faktor & $\begin{array}{l}\text { 1. Pihak yang berwenang dalam kontraktor memiliki kesibukan dan } \\
\text { jadwal yang berlainan dengan pemasok lainnya }\end{array}$ \\
\hline Penyebab & $\begin{array}{l}\text { 2. Pihak kontraktor mengalami kendala Sumber Daya Manusia } \\
\text { dalam proses koordinasi dengan pemasok }\end{array}$ \\
\hline Dampak & $\begin{array}{l}\text { 1. Pemasok berpotensi mengalami terjadinya kesalahan pertukaran } \\
\text { informasi } \\
\text { 2. Pemasok berpotensi menerima komplain dari kontraktor atas } \\
\text { ketidakpuasan dinding beton pracetak yang dipasok }\end{array}$ \\
\hline Strategi & 1. Pemasok melakukan inisiatif untuk melakukan komunikasi dan \\
\hline Preventif & koordinasi secara intensif kepada kontraktor \\
\hline $\begin{array}{l}\text { Strategi } \\
\text { Kuratif }\end{array}$ & $\begin{array}{l}\text { 1.Pemasok menugaskan petugas lapangan untuk memberi informasi } \\
\text { kepada kontraktor apabila terjadi permasalahan dalam proses } \\
\text { pemesanan, pengiriman, dan pemasangan dilapangan }\end{array}$ \\
\hline
\end{tabular}

\section{KESIMPULAN}

Dari uraian dan pembahasan mengenai Analisis Risiko Rantai Pasok Dinding Beton Pracetak Pada Proyek Pembangunan Apartemen Puncak Dharmahusada Surabaya, maka didapatkan kesimpulan sebagai berikut:

1. Diperoleh 9 variabel risiko pada aliran material/fisik, 9 variabel risiko pada aliran finansial, 10 variabel risiko pada aliran informasi, 5 variabel risiko pada aliran relasional, dan 6 variabel risiko pada aliran inovasi yang relevan terkait rantai pasok dinding beton pracetak pada proyek pembangunan Apartemen Puncak Dharmahusada Surabaya.

2. Dari hasil survei utama dan analisis data dari persepsi probabilitas dan dampak risiko, didapatkan risiko dengan katagori tinggi sebagai berikut:

a. Persepsi kontraktor terhadap aktivitas rantai pasok dinding beton pracetak

Variabel risiko yang tergolong kategori tinggi adalah: A3, A5, A11, A14, dan A34

b. Persepsi pemasok terhadap aktivitas rantai pasok dinding beton pracetak

Variabel risiko yang tergolong kategori tinggi adalah: B1, B13, B19, dan B33

3. Dari hasil survei respon risiko yang dilakukan dengan wawancara terhadap pihak-pihak terkait sehingga diperoleh hasil seperti berikut:

a. Persepsi kontraktor terhadap aktivitas rantai pasok dinding beton pracetak

Untuk risiko ketidakstabilan suplai material oleh pemasok kepada pihak kontraktor, maka dilakukan strategi dengan membuat kesepakatan adanya penalty pelanggaran perjanjian dalam pembuatan RFQ (Request for Quotation) yang sudah tertera dalam 
bentuk perjanjian yang harus dipenuhi oleh pemasok. Untuk ketidaksesuaian antara jumlah material yang dikirim oleh pemasok kepada pihak kontraktor dengan jumlah permintaan dari pihak kontraktor, maka dilakukan strategi dengan selalu menjalin komunikasi kepada pihak pemasok untuk memastikan jumlah material yang akan dikirim sesuai PO (Purchase Order) agar tidak terjadi kesalapahamn. Untuk harga yang diberikan oleh pemasok kepada pihak kontraktor kurang kompetitif, maka dilakukan strategi dengan memilih pemasok yang menawarkan harga yang sesuai dengan kualitas bagus pada saat proses TBE (Technical Bid Evaluation). Untuk perubahan harga material yang dipasok akibat eskalasi kenaikan harga material, maka dapat dilakukan strategi dengan menyiapkan anggaran yang berlebih sesuai dengan perkiraan eskalasi harga material dalam 3 tahun terakhir. Sedangkan untuk pembengkakan biaya konstruksi dengan adanya metode konstruksi yang baru, dapat dilakukan strategi dengan memastikan setiap metode konstruksi yang akan dipakai agar anggaran proyek lebih akurat dan tidak mengalami pembengkakan.

b. Persepsi pemasok terhadap aktivitas rantai pasok dinding beton pracetak

Untuk kelangkaan material yang menyebabkan tidak tepat waktu dalam pengiriman, maka dapat dilakukan strategi dengan menyiapkan stok dinding beton pracetak yang berlebih untuk mengantisipasi jika salah satu subpemasok tidak dapat mengirim tepat waktu. Untuk frekuensi pembayaran yang dilakukan oleh pihak kontraktor kepada pihak pemasok, maka dapat dilakukan strategi dengan selalu aktif dalam berkomunikasi dengan bagian keuangan dan logistik pada pihak kontraktor sebelum pengiriman material dan penagihan invoice. Untuk ketidakjelasan kontraktor dalam memberikan informasi, maka dapat dilakukan strategi dengan komunikasi pada pihak kontraktor untuk memastikan jadwal pengiriman dan jumlah material yang dikirim. Dan untuk koordinasi yang lemah dengan kontraktor, maka dapat dilakukan dengan melakukan inisiatif untuk melakukan komunikasi dan koordinasi secara intensif kepada kontraktor.

\section{SARAN}

Dari hasil penelitian ini dapat diberikan saran sebagai berikut:

1. Melakukan penelitian mengenai analisis rantai pasok pada obyek lain seperti kolom, balok, dan plat untuk mengerti kemungkinan-kemungkinan risiko yang akan terjadi.

2. Penentuan skala probabilitas dan skala dampak dapat diteliti lebih lanjut, sehingga analisis risiko akan mendapatkan hasil yang lebih akurat.

\section{DAFTAR PUSTAKA}

[1] C. . Nurcahyo, "Analisis Risiko Rantai Pasok Beton Ready Mix pada Proyek Pembangunan Apartemen di Surabaya," J. Apl., vol. 14, no. 2, pp. 95-102, 2016.

[2] S. Soepiadhy, "Pengaruh Rantai Pasok terhadap Kinerja Kontraktor Bangunan Gedung di Jember," Institut Teknologi Sepuluh Nopember, 2011.

[3] J. L. Cavinato, A. E. Flynn, and R. . Kauffman, The Supply Management Handbook, 7th ed. New York: Mc Graw Hill Book Co., 2006.

[4] Long and et al, "Delay and Cost Overruns in Vietnam Large Construction Project: A Comparison with Other Selected Countries Korean Society of Civil Engineering," J. Civ. Eng., vol. 12, 2008.

[5] I. . Al-Hammad, "Criteria for Selecting Construstion Labour Market in Saudi Arabia," J. Eng. Sci., 2013.

[6] P. M. I. Inc, A Guide To The Project Management Body Of Knowledge 2000 Edition. Pennsylvania: Project Management Institute Inc, 2000. 